\title{
Recognition of Face Identity and Emotion in Expressive Specific Language Impairment
}

\author{
A. Merkenschlager ${ }^{a} \quad H$. Amorosa $^{c} \quad H$. Kiefl $^{b} \quad$ J. Martinius ${ }^{d}$ \\ ${ }^{a}$ Klinik und Poliklinik für Kinder und Jugendliche, Universität Leipzig, Leipzig, ${ }^{b}$ Institutsambulanz für Kinder- und \\ Jugendpsychiatrie und Psychotherapie, Weiden/Oberpfalz, ' ${ }^{C} H e c k s c h e r ~ K l i n i k$ für Kinder- und Jugendpsychiatrie, \\ Abteilung für teilleistungs- und verhaltensgestörte Kinder, und ${ }^{\mathrm{d}}$ Institut und Poliklinik für Kinder- und \\ Jugendpsychiatrie und Psychotherapie, Ludwig-Maximilians-Universität München, München, Deutschland
}

\section{Key Words}

Expressive specific language impairment $\cdot$ Communication skills · Face and emotion recognition

\begin{abstract}
Objective: To study face and emotion recognition in children with mostly expressive specific language impairment (SLI-E). Subjects and Methods: A test movie to study perception and recognition of faces and mimic-gestural expression was applied to 24 children diagnosed as suffering from SLI-E and an age-matched control group of normally developing children. Results: Compared to a normal control group, the SLI-E children scored significantly worse in both the face and expression recognition tasks with a preponderant effect on emotion recognition. The performance of the SLI-E group could not be explained by reduced attention during the test session. Conclusion: We conclude that SLI-E is associated with a deficiency in decoding non-verbal emotional facial and gestural information, which might lead to profound and persistent problems in social interaction and development.
\end{abstract}

Copyright $\odot 2012$ S. Karger AG, Basel
(C) 2012 S. Karger AG, Basel

$1021-7762 / 12 / 0642-0073 / \$ 38.00 / 0$

Fax +41613061234 E-Mail karger@karger.ch www.karger.com

\section{Introduction}

Expressive specific language impairment (SLI-E) according to the 'International Classification of Diseases and Related Health Problems', tenth revision (ICD-10) [1], is characterized by impairment in the development of mostly expressive language skills, not explained by intellectual, sensory, physical, or neurological impairment. The subaverage language functions contrast with normal non-verbal intelligence test results, while any other known disorder that could hinder the normal development of language abilities is excluded.

A number of publications have shown that languageimpaired children are at risk for social impairment [2-4]. In preschool children with language delay, the level of expressive language has a major influence on social and non-verbal communication skills [5]. Few studies have focused on the recognition of facial expressions and faces in children with SLI $[6,7]$. A mixed receptive-expressive language disorder seems to be a particular risk for these handicaps [6]. This contrasts with an often used study design, where language-impaired children serve as a control group (CG) for the face and emotion recognition skills of autistic children [8-10]. Some of these studies

Prof. Dr. Andreas Merkenschlager

Klinik und Poliklinik für Kinder- und Jugendmedizin

Zentrum für Frauen- und Kindermedizin, Universität Leipzig

Liebigstrasse 20a, DE-04103 Leipzig (Germany)

Tel. +49 3419726 320, E-Mail Andreas.Merkenschlager@ medizin.uni-leipzig.de 
suggest that language development, facial identity, and affect recognition are interrelated [11-13].

In our study, we focused on SLI-E because of the strong clinical impression that these children show relevant deficits in processing of non-verbal communicative signals. We tested the performance of SLI-E children in comparison with age-matched normal children in a test of facial identity and affect recognition. Further, we analysed the error profiles with respect to quantitative or qualitative features to uncover possible underlying task solving strategies.

\section{Methods}

\section{Subjects}

Expressive Specific Language Impairment

Participants included 24 children ages $7-11$ years who were diagnosed with expressive specific language impairment (F80.1) according to ICD-10. The participants were recruited from a special education school for language-impaired children or referred to the department for children with developmental and behavioural disturbances. Ten participants attended a special elementary school for language-impaired children. The remaining 14 children were day patients of a child psychiatry hospital specialized in specific language and learning problems. The participants included eight 7 - to 8 -year-old children, and 16 children between the ages of 9 and 11 years. All children were examined individually and extensively by a multiprofessional team and diagnoses were established just prior to inclusion in the study. Most participants had been followed for several years and two child psychiatrists, with longstanding experience in the field of specific language disorders, made the assignment to the diagnostic group SLI-E. Language skills were assessed with the 'Heidelberger Sprachentwicklungstest': subtest VS 'Verstehen von grammatikalischen Strukturen' (Comprehension of Grammatical Structures) was used as a measure of receptive language skills and subtest IS 'Imitation grammatikalischer Strukturen' (Imitation of Grammatical Structures) as a measure of expressive language skills [14]. Additionally, subtests 'Wortverständnis' (Understanding of Words) and 'Bilder zuordnen' (Matching of Pictures) of the 'Psycholinguistischer Entwicklungstest' (PET) for children aged 3-10 years were applied [15]. The PET is the German version of the Illinois Test of Psycholinguistic Abilities.

In order to be included in the diagnostic group SLI-E, there had to be a two-standard deviation discrepancy between measures of language skill and chronological age in addition to a onestandard deviation discrepancy between measures of language skill and measures of non-verbal intelligence. Furthermore, children with difficulties in the comprehension of discourse during a conversational situation were excluded.

\section{Control Group}

Forty normally developing children, age range 7-11 years, with an unremarkable neuropsychiatric history and normal results in a full neurological exam served as controls. Sixteen children were 7 and 8 years old and 24 children aged 9 through 11 years. All these subjects were treated in a children's hospital for somatic complaints; medication affecting psychomotor speed, psychosomatic disorders and painful conditions were excluded.

Inclusion criteria for all children: the non-verbal intelligence quotient (IQ) test result had to be 85 or higher. For all children with SLI-E current IQ test results were available (Hamburg Wechsler Intelligenztest für Kinder - revidierte Fassung; Kaufmann Assessment Battery for Children; Culture Fair Test). The control subjects were tested using Raven's Progressive Matrices.

Additionally, components of visual perception were examined by established measures, which are known to be associated with recognition deficits of facial stimuli (pass criteria in brackets): visual acuity using Snellen test chart for children (at least 6/9 with spectacles allowed), colour vision (colour board of Ishihara, no red-green colour deficiencies), visual field (no visual field deficiency), visual exploration by pointing to triangles between dots on a chart of $1.7 \times 1.2 \mathrm{~m}$ (at least $90 \%$ of triangles indicated), contrast discrimination using Cambridge Low Contrast Gratings (total scores at least 22 for the younger and 24 for the older groups, respectively) $[16,17]$ and visual spatial orientation using Benton's Judgement of Line Orientation Test (JLO raw score transformed into a $z$ score inside $95 \%$ of the normal distribution) $[18,19]$. All participants passed these screening tests for visual perception deficits.

\section{Test Material}

The study was based on a test movie developed and described by Berndl et al. [20], which was used with personal advice and permission by the authors. Basically, the person recognition task consisted of slides presenting five actors or actresses and the children were asked to recognize the person from the actual movie scene. The emotion recognition task had different segments: choice of one of five stationary snaps from the movies representing the actual scene, choosing a line drawing matching its emotional expression, and expressing the scene's emotional information either by a verbal description or by pantomiming it, respectively. There was no time limit for task solving to exclude the influence of psychomotor speed on non-verbal cognitive tasks. Corresponding to each movie scene, one subtest was included twice to control for attention variation. This was done because children with SLI are at increased risk for attention and activity disturbances.

The test consisted of 13 different silent movie scenes presenting mimicry and gestural expression of emotions from everyday life situations (e.g. joy, fear, pain, anger). Each scene was played by a different actor or actress. Performers of the pantomime were young adults; they were shown above the waist line. The projection time for each movie scene was $10 \mathrm{~s}$ leading to a fairly high amount of informational redundancy. At the beginning of each test session training trials were performed until the basics of the test were completely understood.

The perception and recognition of the acting persons and their expressions were evaluated by means of 9 different types of multiple-choice subtests, offered immediately following each movie scene. The subtests require recognition of identity (three subtests) or affect (six subtests). For seven of these subtests, subjects responded non-verbally by pointing to one of five choices displayed on slides using a laser pointer. Just two subtests demanded some verbal processing: one emotion recognition task for a verbal description of the content of the scene, but pantomiming by means 
of facial mimicry and gesture was encouraged and allowed as well; in another emotion recognition task, subjects had to choose one of five phrases, which were associated with the perceived expression. These phrases were written on a slide and read out loud by the test instructor as often as desired by the participant.

Each subtest offered one correct answer among the five possible choices. These tests evaluated recognition of the person with a neutral facial expression, identification of the presented emotional expression in the same person, recognition of the expression in a different person, recognition of the person pantomiming a different expression, and the matching of a line drawing to the scene. Two subtests of the original test were slightly modified to uncouple the test demands from reading and verbal expressive proficiency of the participants. In one subtest, a pantomime of the emotional content of the scene was allowed alternatively to verbally describing it. In the other subtest, the matching simple description of the scene's content was read aloud and not just shown on a screen. In a pilot study, we verified that these phrases were understood even by the youngest preschool children; they were read aloud as often as requested by the participant.

This material has not been used in children before. We decided to use this test for paediatric purposes because of three special qualities: (1) the test presents non-verbal communicative signals in a naturalistic temporal sequence, (2) facial emotion recognition is facilitated by accompanying gestures as in everyday life situations, and (3) movie scenes on a television screen have extraordinary salience for most children, even at very early ages. In a pilot study we applied the test to 105 normal children aged 3 through 14 years and found it well applicable.

\section{Statistical Analysis}

The test results were analysed with respect to quantitative as well as qualitative features, especially with respect to the performance difference between the SLI-E and the CG.

We analysed the total error score, defined as the percentage of all wrong answers in relation to all subtests. In a further analysis we separately scored the results according to person or emotion recognition tasks.

In the pilot study, we found that the performance proficiency increased remarkably between the ages of 8 and 10 years. Therefore, the results of the 7- to 8- and the 9- to 11-year-old children were analysed separately.

The groups were compared using unpaired tests; performance stability for the one subtest presented twice was tested by a paired t test comparing the results for the first and second presentation. A significance level of $p=0.01$ was set for each comparison.

\section{Results}

When comparing the total error scores of the children in the SLI-E groups to those of their age-matched controls, the SLI-E children scored significantly worse than normally developing children ( $\mathrm{p}<0.001$, fig. 1 ). For the 7 - to 8-year-old children, the total error scores (mean \pm SEM) gave the following results: CG $12.27 \pm 1.78$ vs. SLIE $27.1 \pm 1.65[t(22)=4.55, p=0.0002,95 \%$ CI 7.98-21.68]

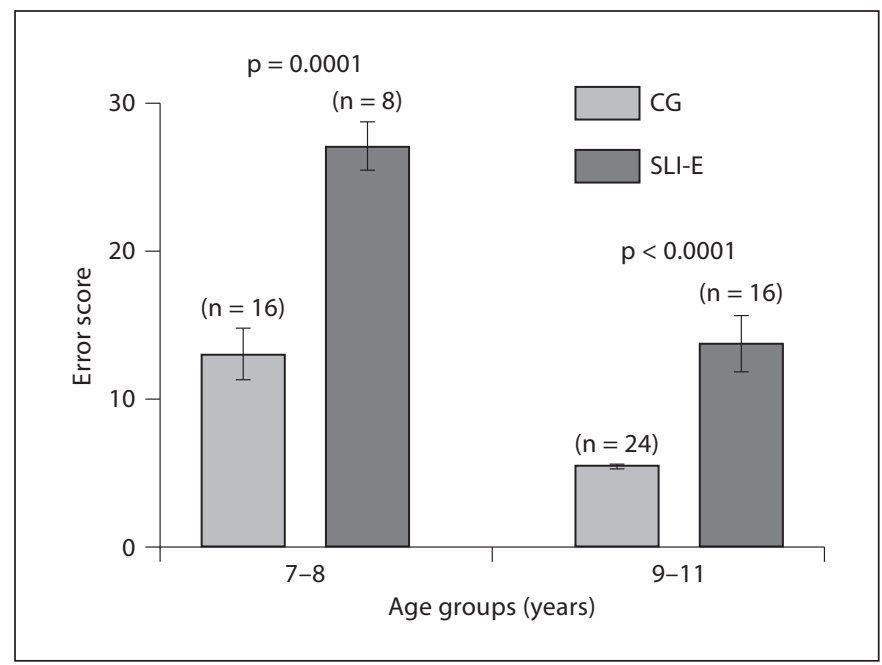

Fig. 1. Comparison of total error score between CG (normally developing children) and children with SLI according to age.

For the 9- to 11-year-olds, the total error scores were CG $5.98 \pm 0.76$ vs. SLI-E $13.75 \pm 1.94[\mathrm{t}(38)=4.24, \mathrm{p}=$ 0.0001, 95\% CI 4.06-11.48].

The detailed error profile analysis revealed that this significant performance difference included person as well as emotion recognition tasks. In all these comparisons there was a significant $(\mathrm{p}<0.0001)$ advantage for the normally developing children (fig. $2 a-d$ ). In detail, for the 7- to 8-year-olds the error scores for identity recognition were $1.55 \pm 0.07$ vs. $3.14 \pm 0.45$ [mean \pm SEM, CG vs. SLI-E, respectively; $\mathrm{t}(22)=5.10$, CI 0.94-2.23; fig. 2a]. For this age group the error scores for emotion recognition were $1.52 \pm 0.05$ vs. $3.64 \pm 0.47$ [CG vs. SLI-E; $t(22)=$ 8.12, 95\% CI 1.57-2.68; fig. 2b]. For the 9- to 11-year-olds the error scores for identity recognition were $0.49 \pm 0.07$ vs. $2.78 \pm 0.42$ [CG vs. SLI-E; $\mathrm{t}(38)=5.01$, CI 1.1-2.59, fig. 2c]. The error scores for emotion recognition were $0.48 \pm 0.04$ vs. $1.58 \pm 0.18$ [CG vs. SLI-E; t $(38)=7.63, \mathrm{CI}$ 0.80-1.39; fig. $2 \mathrm{~d}$ ].

When one compares the performance of the older group of SLI-E children in relation to the younger CG, the SLI-E group scored worse on the identity recognition task $[\mathrm{t}(31)=2.76, \mathrm{p}<0.01$; fig. 3a]. With increasing age, normal children developed an improving proficiency in decoding mimic and gestural information relative to person recognition $[\mathrm{t}(46)=5.49, \mathrm{p}<0.0001$; fig. $3 \mathrm{~b}]$. This clear maturational effect was lacking in the language-impaired children. In the SLI-E group, the 9- to 11-year-olds showed no significant emotion over identity recognition advantage (fig. 3c). 
Fig. 2. Analysis of identity (a, c) and emotion $(\mathbf{b}, \mathbf{d})$ recognition according to age.
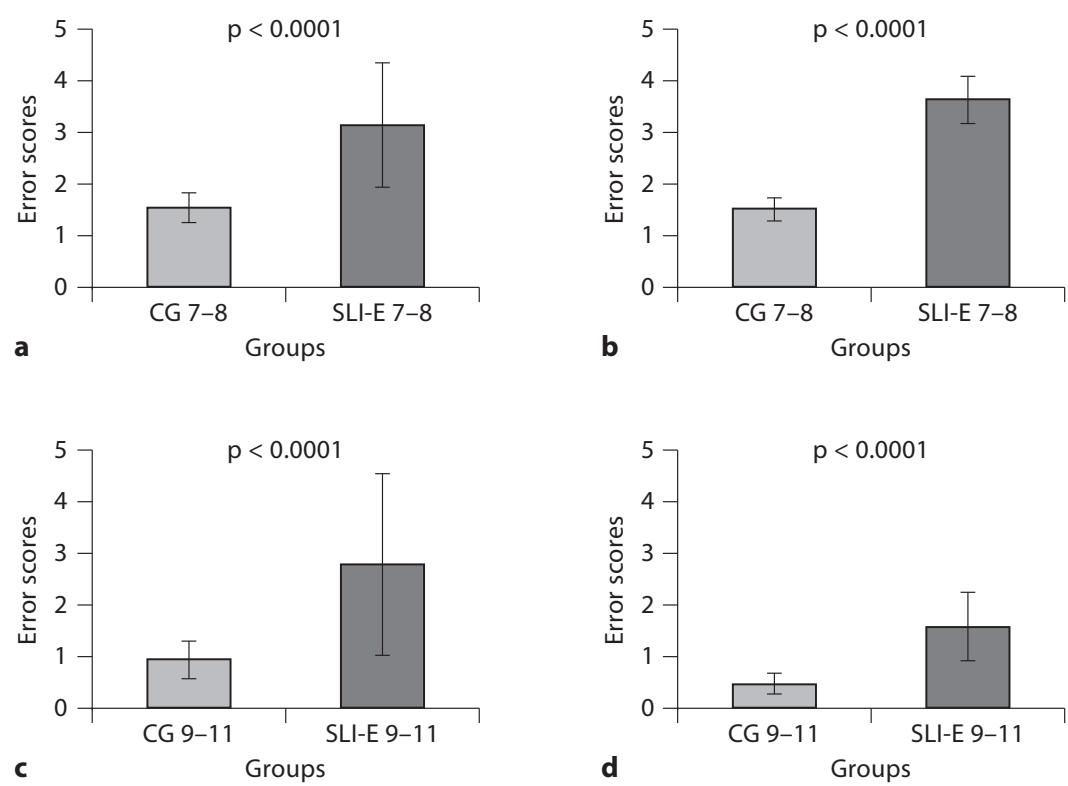

Fig. 3. a Comparison of 7- to 8-year-old normal and 9- to 11-year-old SLI children with respect to identity recognition. b Error scores for identity versus emotion recognition tasks among the 9- to 11-year-old CG. c Same as b, for the 9- to 11-year-old SLI-E group, this effect of age was not found in the 9- to 11-year-old SLI-E. d Comparison of SLI-E children for first and second presentation.
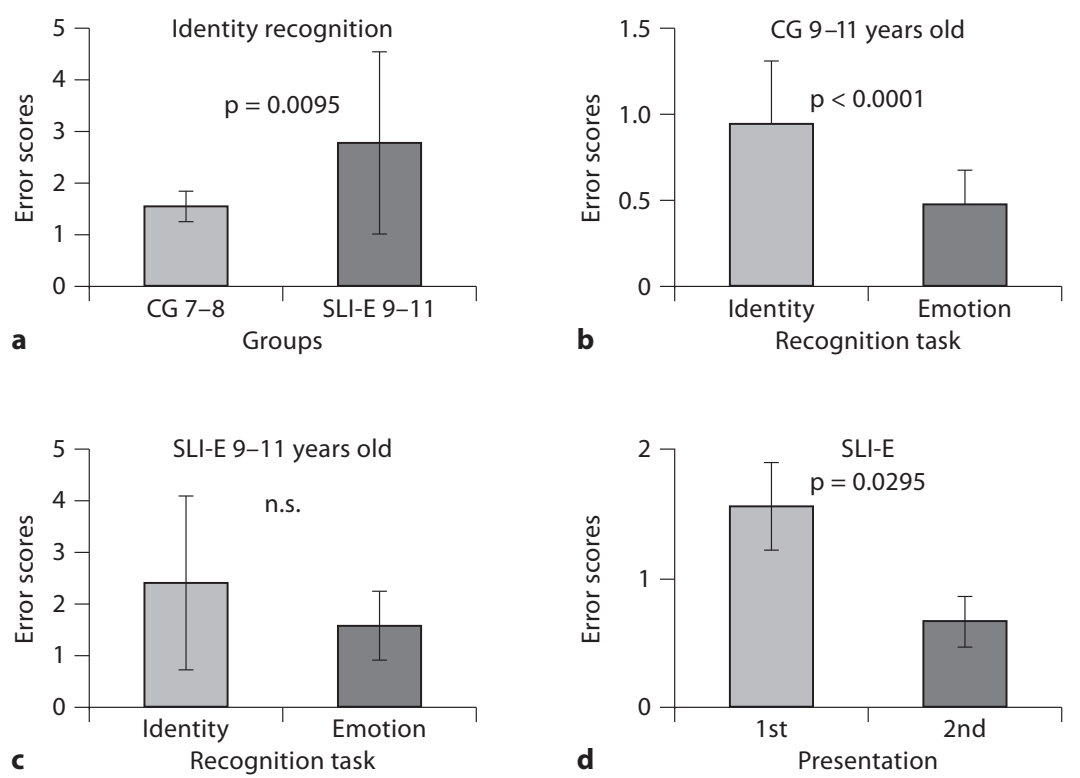

A comparison of identity recognition errors revealed reliance on the same stimulus features in control and SLI-E groups: to the same extent, errors of identity recognition are explained by judgement based on paraphernalia (i.e. features such as a haircut, or beard). A bias for positive emotions was found for all groups: errors in matching the video scene to a line drawing showed a bias for the positive emotion, e.g. a picture with the face of a clown is preferred to that associated with a spoilt meal. 


\section{Control Subtest for Attention Fluctuation}

The analysis of the one subtest that was presented twice as described above did not point to a decrease of attention in both control and, especially, study subjects (fig. 3d).

\section{Discussion}

Both age groups of language-impaired children achieved a significantly higher total error score than the groups of normal children. These results argue for significant recognition deficits of facial identity and mimicgestural expression in primary school age children with SLI-E. Both person and affect recognition seem to be impaired.

Based on the detailed error analyses of the study, we deduce some consistencies between SLI-E and normally developing children. All groups were strongly influenced by paraphernalia when judging face identity. The distractive effect of paraphernalia in children's ability of face recognition is well known [21,22].

Another agreement between the normally developing and the SLI-E group is represented by a bias for positive emotions during the association tasks (matching mimicgestural expression and an adequate cartoon). Possibly, this can be explained by a positivity effect, which might apply to all study subjects: positive emotions might increase feelings of familiarity [23].

Because this paradigm is used as a non-verbal memory test, it is justified to speculate about non-verbal memory deficits in the SLI-E group as an explanation for reduced face recognition skills [24]. Short-term memory deficits might play a role in the problematic language acquisition of children with SLI [25], but we think that the inferior performance of the SLI-E children in our study is just to a minor extent explained by memory difficulties. The test application immediately after the video presentation in conjunction with the control subtest scores make it unlikely that memory deficits had a strong influence on the results. More importantly, memory impairments in SLI seem to be domain-specific, affecting predominantly verbal processing and not visual domains [26]. Additionally, a poor short-term memory capacity was found in mixed receptive-expressive language impairment, not in expressive language impairment [27].

Of utmost importance is the result that age-dependent skill improvement of normally developing children in emotion recognition is lacking in SLI-E children. This suggests a maturational delay or disturbance of non-verbal emotion recognition in these children, and suggests emotion recognition as a quite specifically disturbed domain in SLI-E.

In accordance with the domain-general theory of SLI [28], our results could reflect a variety of maladaptions in brain systems required not just for comprehension and production of language but for processing of the human face, mimic and gesture. Given the possibility of such a widespread cognitive impairment, it is noteworthy that the profile of the SLI-E results differs clearly from children with a global cognitive deficiency as in the case of mental retardation. Children with mental retardation score significantly poorer than normally developing children in tasks of face identification, but mental retardation is not associated with a disturbance in facial affect recognition $[29,30]$. In contrast to these literature data, both age groups of SLI-E children had a predominant deficit in emotion recognition. They also differed from normally developing children, who developed an advantage of emotion decoding over identity recognition around the age of 10; at this age, in normal children the adult performance level seems to be reached [31,32].

Our test results could have been influenced by attention fluctuation or deficit. Children with attention-deficit disorder (ADD) exhibit a general deficit in decoding emotional facial expressions [33]. Children with SLI show additional attention deficits $[28,34,35]$. Co-occurrence of ADD [36] or an increased risk for ADD [37] might be a possible explanation to the visual perception disadvantage. The control subtest scores strongly argue against a prevailing influence of attention fluctuations as an explanation for the low performance level of the SLI-E group. In addition, there was no linear relation between error probability and test duration.

One limitation of the study could be that two subtests required, at least partially, verbal performance skills, but their contribution to the total error score of the SLI-E groups was of minor relevance. Even when excluding these two items from analysis, the results did not change substantially. We explain this by our modification of the original test: instead of verbally describing the scene's content, pantomiming was encouraged and accepted. When a read-aloud phrase had to be chosen, this was read as often as desired by the subjects. In a pilot study using the material, these phrases were convenient even for the youngest preschoolers. The highest error scores for both normal and SLI-E children were found for the non-verbal task. The association task of matching a cartoon to the content of the scene was the most difficult item. But, still it has to be considered that all instructions were given verbally, even when as much effort as possible was made for 
the instructions to be understood by means of repeating and reformulating and demonstrating them non-verbally.

Another limitation might be the choice of the CG, because anxiety and stressful experiences - possible consequences of somatic illnesses - might modify emotional memory retrieval $[38,39]$. To exclude the possible influences on the sensitivity to face identity and emotion, it would be useful to establish a CG of physically healthy children.

In summary, our study suggests impaired performance in recognizing non-verbal emotion recognition in SLI-E, which might be an important additive causal factor for its social communication deficits.

\section{Acknowledgements}

The authors are grateful to Prof. Dr. O.-J. Grüsser ${ }^{\dagger}$ and Dr. K. Berndl for giving personal advice and introduction to the test material and the permission to use it and publish the data.

\section{Disclosure Statement}

There is no conflict of interest.

\section{References}

1 World Health Organisation (WHO) 2010: International Statistical Classification of Diseases and Related Health Problems, 10th revision. http://apps.who.int/classifications/ apps/icd/icd10online/

2 Beitchman JH, Wilson B, Brownlie EB, Walters $\mathrm{H}$, Inglis A, Lancee W: Long-term consistency in speech/language profiles. II. Behavioral, emotional, and social outcomes. J Am Acad Child Adolesc Psychiatry 1996;35: 815-825.

3 Berg JS, Brunetti-Pierri N, Peters SU, Kang SH, Fong CT, Salamone J, Freedenberg D, Hannig VL, Prock LA, Miller DT, Raffalli P, Harris DJ, Erickson RP, Cunniff C, Clark GD, Blazo MA, Peiffer DA, Gunderson KL, Sahoo T, Patel A, Lupski JR, Beaudet AL, Cheung SW: Speech delay and autism spectrum behaviors are frequently associated with duplication of the 7q11.23 WilliamsBeuren syndrome region. Genet Med 2007;9: 427-441.

4 Brinton B, Spackman MP, Fujiki M, Ricks J: What should Chris say? The ability of children with specific language impairment to recognize the need to dissemble emotions in social situations. J Speech Lang Hear Res 2007;50:798-811.

5 Lord C, Pickles A: Language level and nonverbal social-communicative behaviors in autistic and language-delayed children. J Am Acad Child Adolesc Psychiatry 1996;35: 1542-1550.

6 Robel L, Vaivre-Douret L, Neveu X, Piana H, Perier A, Falissard B, Golse B: Children with mixed language disorder do not discriminate accurately facial identity when expressions change. Eur Child Adolesc Psychiatry 2008;17:507-515.

7 Creusere M, Alt M, Plante E: Recognition of vocal and facial cues to affect in languageimpaired and normally-developing preschoolers. J Commun Disord 2004;37:5-20.
8 Gross TF: Recognition of immaturity and emotional expressions in blended faces by children with autism and other developmental disabilities. J Autism Dev Disord 2008;38: 297-311.

9 Gross TF: The perception of four basic emotions in human and nonhuman faces by children with autism and other developmental disabilities. J Abnorm Child Psychol 2004; 32:469-480.

10 Loucas T, Charman T, Pickles A, Simonoff E, Chandler S, Meldrum D, Baird G: Autistic symptomatology and language ability in autism spectrum disorder and specific language impairment. J Child Psychol Psychiatry 2008;49:1184-1192.

11 Ozonoff S, Pennington BF, Rogers SJ: Are there emotion perception deficits in young autistic children? J Child Psychol Psychiatry 1990;31:343-361.

12 Hobson RP, Ouston J, Lee A: What's in a face? The case of autism. Br J Psychol 1988; 79:441-453

13 Hobson RP: Methodological issues for experiments on autistic individuals' perception and understanding of emotion. J Child Psychol Psychiatry 1991;32:1135-1158.

14 Grimm H, Schöler H: Der Heidelberger Sprachentwicklungstest (HSET), ed 2. Göttingen, Hogrefe, 1991.

15 Angermaier M: Psycholinguistischer Entwicklungstest, ed 2. Weinheim, Beltz, 1977.

16 Nielsen LS, Nielsen SK, Skov L, Jensen H: Contrast sensitivity - an unnoticed factor of visual perception in children with developmental delay: normal data of the Cambridge Low Contrast Gratings test in children. J Child Neurol 2007;22:151-155.

17 Wiklins A, Della Sala S, Somazzi LNI: Agerelated norms for the Cambridge Low Contrast Gratings, including details concerning their design and use. Clin Vision Sci 1988;2 201-212.
18 Riva D, Benton AL: Visuospatial judgement: a cross-national comparison. Cortex 1993; 29:141-143.

19 Benton AL, Varney NR, Hamsher KS: Visuospatial judgement. Arch Neurol 1978:364367.

20 Berndl K, Dewitz W, Grüsser OJ, Kiefer RH: A test movie to study elementary abilities in perception and recognition of mimic and gestural expression. Eur Arch Psychiatry Neurol Sci 1986;235:276-281.

21 Freire A, Lee K: Face recognition in 4- to 7-year-olds: processing of configural, featural, and paraphernalia information. J Exp Child Psychol 2001;80:347-371.

22 Flin RH: Development of face recognition: an encoding switch? Br J Psychol 1985;76: 123-134.

23 Verde MF, Stone LK, Hatch HS, Schnall S: Distinguishing between attributional and mnemonic sources of familiarity: the case of positive emotion bias. Mem Cognit 2010;38: 142-153.

24 Montgomery JW, Magimairaj BM, Finney MC: Working memory and specific language impairment: an update on the relation and perspectives on assessment and treatment. Am J Speech Lang Pathol 2010;19:78-94.

25 van Daal J, Verhoeven L, van BH: Cognitive predictors of language development in children with specific language impairment (SLI). Int J Lang Commun Disord 2009;44: 639-655.

26 Baird G, Dworzynski K, Slonims V, Simonoff E: Memory impairment in children with language impairment. Dev Med Child Neurol 2010;52:535-540

27 Nickisch A von KR: Short-term memory (STM) constraints in children with specific language impairment (SLI): are there differences between receptive and expressive SLI? J Speech Lang Hear Res 2009;52:578-595. 
28 Marton K: Visuo-spatial processing and executive functions in children with specific language impairment. Int J Lang Commun Disord 2008;43:181-200.

29 Weisman J, Brosgole L: Facial affect recognition in singly diagnosed mentally retarded people and normal young children: a methodological comparison. Int J Neurosci 1994; 75:45-55.

30 Brosgole L, Gioia JV, Zingmond R: Facialand postural-affect recognition in the mentally handicapped and normal young children. Int J Neurosci 1986;30:127-144.

31 Ekman P, Oster H: Facial expressions of emotion. Annu Rev Psychol 1979;30:527554.

32 Grüsser OJ, Selke T, Zynda B: A developmental study of face recognition in children and adolescents. Hum Neurobiol 1985;4:33-39.
33 Pelc K, Kornreich C, Foisy ML, Dan B: Recognition of emotional facial expressions in attention-deficit hyperactivity disorder. Pediatr Neurol 2006;35:93-97.

34 Stevens C, Sanders L, Neville H: Neurophysiological evidence for selective auditory attention deficits in children with specific language impairment. Brain Res 2006;1111: 143-152.

35 Noterdaeme M, Amorosa H, Mildenberger K, Sitter S, Minow F: Evaluation of attention problems in children with autism and children with a specific language disorder. Eur Child Adolesc Psychiatry 2001;10:58-66.
36 McGrath LM, Hutaff-Lee C, Scott A, Boada R, Shriberg LD, Pennington BF: Children with comorbid speech sound disorder and specific language impairment are at increased risk for attention-deficit/hyperactivity disorder. J Abnorm Child Psychol 2008;36:151-163.

37 Snowling MJ, Bishop DV, Stothard SE, Chipchase B, Kaplan C: Psychosocial outcomes at 15 years of children with a preschool history of speech-language impairment. J Child Psychol Psychiatry 2006;47:759-765.

38 Cooper RM, Rowe AC, Penton-Voak IS: The role of trait anxiety in the recognition of emotional facial expressions. J Anxiety Disord 2008;22:1120-1127.

39 el-Miedany YM, el-Rasheed AH: Is anxiety a more common disorder than depression in rheumatoid arthritis? Joint Bone Spine 2002; 69:300-306. 